\title{
El Caso. Aproximación histórico-periodística del semanario español de sucesos
}

Recibido: 19 de marzo de 2012

Aceptado: 27 de junio de 2012

Publicado: 31 de octubre de 2012
Rosa Rodríguez Cárcela

rrodriguez@eusa.es

Universidad de Sevilla (España)

Resumen: El artículo hace un estudio, histórico y periodístico, del semanario español de sucesos El Caso, que se publicó durante más de 40 años. Se analiza su evolución histórica, desde la dictadura de Franco hasta la democracia, así como su estilo y sus llamativas portadas. Fue uno de los periódicos de mayor éxito en la España del siglo XX, supuso un ejemplo de prensa popular rentable y su director, Eugenio Suárez, creó uno de los primeros grupos de prensa en España.

Palabras clave: Historia del periodismo en España, periodismo especializado, periodismo de sucesos, crímenes, estilo periodístico, portadas de periódicos, grupos de comunicación.

Abstract: The article is an historical and journalistic study about El Caso, an events weekly newspaper, which was published during 40 years in Spain. We analyze the historic evolution of this publication, from Franco's dictatorship to the coming of the democracy, as well as its style and its striking covers. This newspaper was one of the most successful in Spain over the 20th century, was a remarkable example of profitable popular press, and its director, Eugenio Suárez, created one of the first Spanish Media groups.

Key words: History of Journalism in Spain, Specialized Journalism, Accident and Crime Reports, Crimes, Journalistic Style, Newspaper Covers, Media Groups. 


\section{Introducción}

El 11 de mayo de 1952 salía a la calle El Caso, el semanario de sucesos de mayor éxito en la España del siglo XX y que tuvo una vigencia de más de cuarenta años. Esta publicación constituyó un fenómeno comunicativo y social, marcando un hito en el periodismo especializado.

Su fundador y editor, Eugenio Suárez, forjó un estilo propio de la información de sucesos ${ }^{1}$. El Caso ha sido un periódico que, desde el punto de vista de la comunicación, merece un análisis detallado por ser un modelo de prensa especializada en la temática de los sucesos y por la popularidad que tuvo entre los lectores durante varias décadas. Un producto periodístico que fue emergiendo y logró convertirse en uno de los periódicos de mayor tirada nacional durante la segunda mitad del siglo pasado.

También supone un ejemplo destacado de prensa popular rentable que utilizaba el recurso del sensacionalismo (sobre todo en su aspecto formal y en el tratamiento gráfico de sus portadas) pero sin caer en el amarillismo, en el engaño a los lectores.

El Caso simboliza, sin duda, una época reciente del periodismo español, un estilo periodístico cercano a los lectores, popular, donde primaba el "reporterismo de calle", la investigación y la búsqueda de la noticia en su vertiente más extrema y sorprendente: el crimen, la delincuencia o los hechos curiosos o extraordinarios.

Actualmente, el periodismo en España está falto de ese periodismo de calle, vivo, donde se buscaba la exclusiva y se indagaban todos aquellos hechos "de interés humano". Hoy prima un periodismo más institucionalizado, más gris, donde el reportero de calle ha sido sustituido por el redactor de oficina, que recibe las notas de prensa y las informaciones de agencia y elabora la información a golpe de llamada de teléfono o de rastreo en Internet.

El Caso fue además un producto periodístico adelantado en su tiempo, ya que gracias a la rentabilidad que generó este semanario, surgió un importante conglomerado de periódicos y revistas que conformó uno de los primeros grupos de prensa que se creó en España, liderado por Eugenio Suárez.

El Caso se convirtió en uno de los semanarios especializados que contó con los mayores índices de lectura entre los años cincuenta y ochenta. De los 13000 ejemplares de tirada del número inicial, pasó, al cumplirse su primera década (1962), a los 150000 de venta. Diez años más tarde, según el control de la Oficina de Justificación de la Difusión (OJD), El Caso alcanzaba una tirada de 208535 ejemplares. Cifra sólo superada en la prensa escrita de los años setenta por tres semanarios del corazón, según estima Casasús².

1 Esta expresión (predominante en la Península) hace referencia a la información abocada al acontecer policial y judicial, así como a la cobertura de hechos delictivos y luctuosos.

2 Interpretamos que Casasús (1985a: 164) se refiere a las revistas de "información rosa” de España, tales como ¡Hola!, Diez Minutos y Pronto. 
Estamos, por tanto, ante un periódico que marcó estilo y creó escuela entre los periodistas durante cuatro décadas en España; mantuvo un éxito continuado y creciente entre los lectores y permitió constituir en los años setenta una empresa periodística rentable, germen de los actuales grupos de comunicación que se crearon en España en las décadas posteriores.

\section{Metodología}

En este artículo se analizan y describen, desde el punto de vista formal y de contenido, las características de un semanario especializado en sucesos, El Caso. También hacemos un recorrido histórico de uno de los periódicos de mayor duración en la España del siglo XX (un total de 45 años), informando e interpretando las noticias relacionadas con el mundo del delito, los siniestros y hechos curiosos y sorprendentes. Recorrido que comprende un período que abarca la segunda mitad del siglo pasado (1952-1997).

Los datos que se aportan se han elaborado tomando como referencia las fuentes bibliográficas, especialmente el libro de Rada (2011) que reproduce ejemplares completos y una selección de portadas, tratados de forma digital. Asimismo, las fuentes personales, como son las entrevistas realizadas a Juan Carlos Arias (2008 y 2011), quien fue redactor de El Caso en los años ochenta. Además, se ha contado con copias de portadas y páginas interiores de ejemplares de este semanario facilitados a la autora por Arias. También ha sido importante la recopilación de datos publicados en la prensa escrita, así como en Internet.

Por tanto, el artículo pretende hacer una aportación tanto histórica y de análisis descriptivo de uno de los periódicos de mayor tirada y repercusión social en España. Todo un fenómeno comunicativo en la prensa escrita del siglo XX.

\section{Evolución histórica}

El Caso salía a la calle por primera vez el 11 de mayo de 1952. Su redacción y administración estaban ubicadas en Madrid (calle Jordán $N^{\circ} 1$ ). Su director, Eugenio Suárez. El editorial de este número señalaba su ideario, propósitos e intenciones. Recogemos un extracto de sus principales ideas:

“Ante ti lector una nueva revista. Una revista más que busca llegar a complacer, a rellenar esa afición tan extendida en todas las clases sociales y que se llama curiosidad por la vida de los otros.

Ahora bien; nada de morbosas curiosidades, sino el humano interés por lo que ha sucedido fuera de nuestro portal, quizá en la casa de al lado, quizá en el otro hemisferio. Los que hacemos esta nueva revista hemos de andar con mucho cuidado: el material del que nos surtimos es algo palpitante, vivo. Una vez, los parientes de la inocente víctima; otra vez será el victimario, cuando aguarde esas horas dramáticas que le queden como últimas.

Habrá, claro está, la nota chusca el suceso pintoresco, el caso gracioso, el timo original, cuando, secretamente, aplaudamos el ingenio del timador y reconozcamos que el estafado se lo tenía merecido. 
Las Comisarías, las Brigadas, los Juzgados, el Equipo, el Depósito, los bomberos nos conocen ya, y siempre que ocurra algo de alguna importancia, crimen, robo, estafa, incendio, etcétera, allí estará un representante de EL CASO. Y no sólo en los momentos trágicos, sino en aquellos otros en los que informemos de algo grato, algún servicio de la Policía que redunde en general beneficio, el rescate de algún prisionero, el salvamento de gentes en peligro, etc.

No se esperen, pues, truculencias sanguinarias en estas páginas. Sería de mal gusto, y además, duraríamos poco en el favor del público. EL CASO es, simplemente, informativo.

EL CASO te informará, lector de esa humanidad tremendamente vital. No esperes la fotografía truculenta en la que una equis señala el lugar donde fue hallado el brazo izquierdo del anciano descuartizado. No; unas veces te aleccionará sobre los últimos timos, para que el desaprensivo no sorprenda tu buena fe. Otras, relatará el heroísmo del policía que se jugó la existencia para defender la vida o la propiedad de alguien en peligro; las aventuras de la gente audaz... Reflejaremos autorizadas opiniones de expertos y, en suma, procuraremos que esta revista sea amena, aleccionadora y honradamente informativa".

El Caso tiene dos etapas diferenciadas:

- La primera, dirigida por Eugenio Suárez, su fundador y propietario, que dura un total de 35 años, desde la aparición de su primer número en 1952 hasta 1987, año en que dejó de ser editado por Suárez.

- La segunda etapa, de menor duración, fue la de Joaquín Abad, periodista y empresario que adquirió la cabecera de este periódico y se convirtió en el nuevo propietario hasta su definitiva desaparición el 24 de septiembre de 1997 que se imprimió por última vez.

Dentro de la primera etapa de El Caso, podemos establecer dos períodos históricos: el primero (1952-1975), coincidiendo con el régimen del general Franco; y otro segundo período (1976-1987), que comprende la transición y la democracia. El primero de estos, que duró 23 años, fue probablemente el de mayor importancia desde el punto de vista periodístico, económico y social; es decir, como fenómeno comunicativo hasta la fecha desconocido, por su éxito de ventas y por su repercusión social.

Como señala Rada (2011), este periódico marcó un antes y un después en la historia reciente del periodismo español, al divulgar noticias sobre crímenes y hechos delictivos que ningún otro medio se atrevía a publicar durante la dictadura de Francisco Franco. Supo zafarse hábilmente de la censura, aunque no sin problemas, y rompió con el silencio existente en torno a la difusión de los sucesos.

Pese a las limitaciones informativas existentes en esos años, ya que las autoridades sólo permitían la publicación de un asesinato a la semana, El Caso adquirió cada vez mayor atención y protagonismo en la sociedad y se convirtió en el periódico de mayor venta. Como dato a destacar, a finales de los años cincuenta consiguió colocar en el mercado casi 
medio millón de ejemplares en un solo día. Tal fue el impacto de sus noticias exclusivas, reportajes y crónicas, que contribuyó a acercar la lectura en pueblos olvidados:

“El Caso constituyó un fenómeno mediático. Divulgó los sucesos que se producían en un país cerrado casi por completo a la información. Fue testigo de la España real y profunda, oscurantista en demasiadas ocasiones, frente a la oficial que pretendía mostrar el régimen... Poco a poco fue abriéndose camino ofreciendo temas candentes. Unas veces por su morbo, otras por su misterio y, las más, porque nadie se atrevía hasta entonces a divulgar hechos trágicos. Trató de ser un fiel reflejo de una población desarmada ideológicamente que en muchas ocasiones arreglaba sus desavenencias de forma primitiva. La mayor parte de las veces motivadas por disputas de lindes, despechos, herencias, rivalidades" (Rada, 2011: 13).

El Caso se encargó de recoger y difundir una parte de la historia de España: la crónica delictiva e insólita de nuestro país. Semana a semana informaba acerca del lado más sangriento, desagradable y siniestro de la sociedad; pero también el más humano, extraño, curioso, y sorprendente. De hecho, por su redacción han desfilado una buena parte de periodistas que actualmente son considerados veteranos y maestros. En su larga existencia ha sido desacreditado y denostado, también admirado y envidiado. En 1987 cumplió su 35 aniversario y eso, en prensa escrita, es ya todo un éxito, prueba evidente del interés por la información de sucesos en los lectores.

La primera etapa de El Caso (la de Eugenio Suárez) fue, como hemos indicado, de éxito y apogeo. El primer número se publicó el domingo 11 de mayo de 1952, a un precio de 2 pesetas y una tirada de 13000 ejemplares. Tenía 16 páginas, en formato tabloide y texto apretado.

Eugenio Suárez, quien fue redactor de $M a d r i d^{3}$, creó en este diario una sección titulada "El Caso de...", que tuvo mucho éxito entre los lectores y, por este motivo, decidió fundar su propio periódico de sucesos. Las autoridades administrativas permitieron la nueva publicación, tras numerosas gestiones y trámites burocráticos.

La Dirección General de Prensa había autorizado la creación de este periódico con la condición expresa de no difundir más de dos delitos con sangre a la semana. Debido al éxito que consiguió El Caso en sus cuatro primeros números, el límite permitido de asesinatos se redujo a uno semanalmente, lo que obligó a seleccionar a partir de entonces el crimen que tuviera mayor interés periodístico (figuras 1 y 2). Esta actitud restrictiva de la autoridad se debió a que la imagen del país debía transmitir paz y tranquilidad y a los gobernantes no les interesaba que se difundiera un exceso de criminalidad.

3 Publicación periodística fundada por Juan Pujol Martínez en 1939. Debido a su aperturismo mostrado en la década de los sesenta fue clausurado en noviembre de 1971 
Figuras 1 y 2: portadas del semanario El Caso.
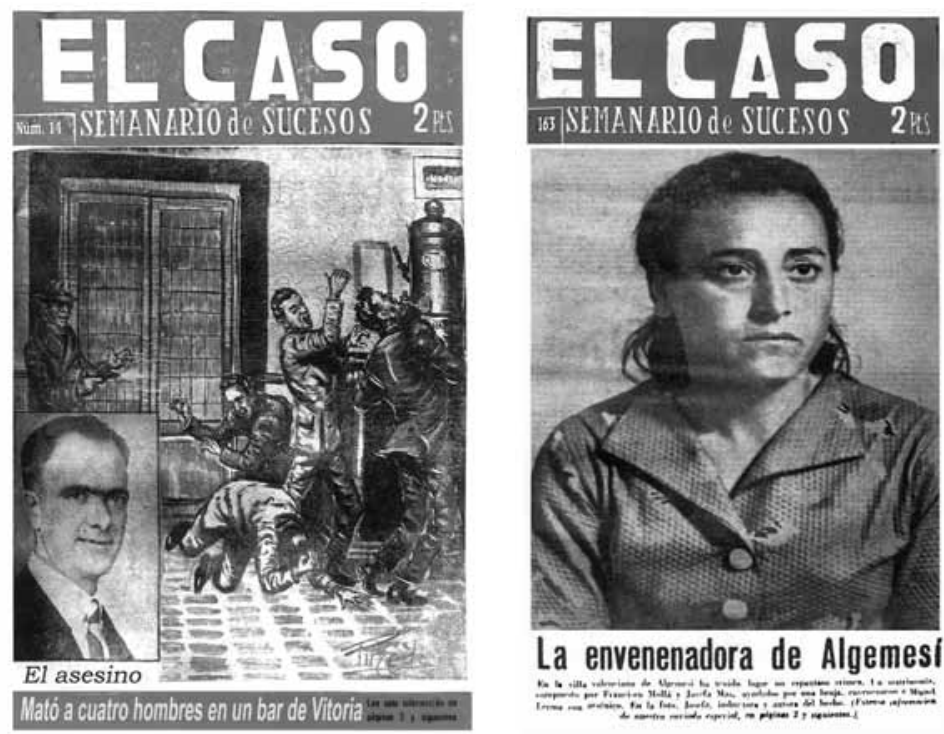

La envenenadora de Algemesi

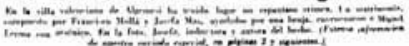

Fuente: archivo personal.

Franco fue más allá de ese pensamiento restrictivo y permitió, en opinión de Rada (2011: 14), que durante más de dos décadas saliera a la calle El Caso, porque los ciudadanos, al estar distraídos con noticias de crímenes y otros sucesos delictivos y asombrosos, no pensarían en cuestiones políticas. En esta línea, ya se había manifestado anteriormente Umbral (1993: 7) cuando escribió un artículo sobre la historia del semanario:

“Era una manera de dar 'España real' contra 'España oficial' de la dictadura. Los sucesos fueron una tercera vía para dar verdad del país (como el 'Pascual Duarte' de Cela, en muy diferente y altísimo nivel literario). Franco permitió $\mathrm{El}$ Caso porque pensaba que la gente, distraída con el crimen de la portera, la gata con alas o el hongo milagroso, se iba a despolitizar, como así fue".

En esencia, era un periódico que informaba sobre temas ajenos a la política. Así servía de medio para el entretenimiento y para saciar el morbo innato del ser humano. La publicación de los sucesos en sus páginas fue, en cualquier caso, una vía para dar a conocer la realidad del país, un reflejo de una parte de la sociedad española, en su aspecto más violento, sorprendente e inusual. Con la puesta en marcha de El Caso comenzaba en España una de las aventuras editoriales y periodísticas más importantes e interesantes del periodismo de la segunda mitad del siglo XX.

En sus inicios la sede de este periódico estaba ubicada en un pequeño piso de Madrid y se imprimía en los talleres del diario Informaciones. En su contraportada se anunciaba una marca suiza de relojes, que sirvió de apoyo económico a El Caso en sus primeros números. 
Caño (2007) detalla el surgimiento de este producto periodístico que, de la nada, fue emergiendo y logró convertirse en uno de los periódicos de mayor tirada nacional durante casi cuatro décadas:

“El superingenioso y otrora célebre editor, Eugenio Suárez, lanzó El Caso sin un duro: financió la compra de papel y la impresión de su semanario de sucesos con el adelanto de pago de seis páginas de publicidad de un fabricante de relojes".

Su equipo redaccional estaba compuesto por los periodistas José María de Vega, Enrique Rubio (quien fue delegado en Barcelona), José Quílez y Margarita Landi; así como los fotógrafos Isidro Cortina y Manuel de Mora y el dibujante Josechu Pinédo.

El Caso tuvo, desde el principio, unas tiradas enormes, con acogida inmediata entre los lectores y la sociedad de aquellos años, convirtiéndose en uno de los periódicos con mayor difusión e índices de lectura. Los 13000 ejemplares semanales del primer número fueron creciendo a cientos de miles, aunque su audiencia era mucho mayor, ya que era normal que se leyera en voz alta y en grupo. Fue calificado por algunos sectores periodísticos y sociales de forma despreciativa como el "diario de las porteras", pero la realidad de las cifras de tirada y difusión demostraron que no sólo lo leían las conserjes, sino un amplio sector de la población española, integrado por las clases trabajadoras, medias y acomodadas y los propios cuerpos de Seguridad, tanto la Guardia Civil como la Policía. También tuvo el mérito de servir como medio de alfabetización e información en los pueblos más alejados.

Los sucesos sangrientos en la década de los cincuenta se publicaban minoritariamente en la prensa escrita, ya que era una temática sujeta a la censura. Los censores también manipulaban la realidad en las noticias de sucesos para que parecieran menos violentas y se transmitiera una imagen de paz y orden social. Según aclara Eugenio Suárez, una de las causas del rápido éxito del semanario se debió paradójicamente a la censura:

"Porque los sucesos, ocurridos en lugares alejados de la capital y que despertaban la curiosidad de la gente, se controlaban menos ya que a la censura de Madrid eso no le importaba nada. La verdad es que tuvimos pocos tropiezos. Se nos prohibía usar el vocablo ‘apareció el cuerpo semidesnudo'; pues nos las ingeniábamos y decíamos 'semivestido”” (San Andrés, 1987: 87).

En esta primera etapa, estuvo racionada la información criminal por el Ministerio de Información y Turismo de turno, debido no sólo a las propias restricciones políticas, sino también por las quejas de algunas asociaciones de padres de familia, órdenes religiosas, cofradías seglares y colectivos puritanos que consideraban lesionados sus derechos por el despliegue que se realizaba en torno a un suceso violento. Enrique Rubio, redactor de $E l$ Caso desde el primer número, explica que la Dirección General de Prensa de la época le tenía advertido a este periódico que no podían publicarse en sus páginas violaciones y otros hechos escabrosos. Asimismo, indica que algunos religiosos no veían con buenos ojos esta publicación e incluso llegaron a criticar su existencia:

“Críticas que el director del semanario cortó solicitando un asesor clerical del obispado madrileño, al que señaló un buen sueldo por su dura tarea, que consistió en no cargarse ni una cuartilla y llevarse muy bien con todos nosotros" (Quesada, 2007: 34). 
En la década de los cincuenta, fue el ministro de Información y Turismo, Gabriel AriasSalgado, el que estuvo a punto de conseguir que El Caso no volviera a publicarse, ya que estimaba que algunos de sus contenidos y tratamientos informativos eran inmorales. Afortunadamente, fue el Obispado de Madrid quien concedió la autorización para que siguiera editándose, al reconsiderarse que debía ser la Iglesia quien pasara la censura eclesiástica.

Por tanto, durante esta primera etapa, El Caso sólo pudo publicar un delito de sangre por número. A pesar de todo ello, se interpusieron escasas demandas al semanario, de las cuales no se perdió ninguna.

En la década de los sesenta, El Caso continuó con el estilo que tan buenos resultados había cosechado. La censura continuaba siendo un freno para poder publicar más de un crimen a la semana, aunque la aparición de la Ley de Prensa e Imprenta de 1966 (la "Ley Fraga") suavizó, al menos aparentemente, la difusión de los hechos trágicos. Esta nueva normativa, que sustituyó a la anterior Ley de Prensa de 1938, mantenía la censura, aunque bajo una apariencia más sutil y liberalizadora.

A partir de 1970, El Caso amplió sus contenidos informativos más allá de los sucesos e incorporó las denominadas "noticias del corazón", la crónica social y los hechos pintorescos; también modernizó técnicamente el periódico. En su cabecera ya no figuraba la denominación "Semanario de sucesos", sino "Semanario popular". Fue un período marcado por los cambios, tanto de dirección y redacción, como técnicos y de diseño.

Fue en septiembre de 1976 cuando esta publicación anunciaba el inicio de una "nueva y pujante etapa, ampliando su redacción y sus colaboradores" ( $A B C, 1976: 25)$. El cambio más fehaciente se produjo con el nombramiento del periodista Juan Caño Díaz como director del semanario en sustitución de José María de Vega, que pasaba a desempeñar un cargo de asesor y directivo en la empresa editora de Eugenio Suárez.

Antes de acceder a este puesto, Caño Díaz había sido redactor-jefe de la sección de reportajes de la agencia Europa Press, jefe de la delegación de la agencia Efe en Londres y Washington, jefe de gabinete de prensa del Ministerio de Agricultura y subdirector de Sábado Gráfico (revista editada por la misma empresa de El Caso). Comenta su experiencia como director del semanario y los cambios introducidos en su contenido, que ya no eran exclusivamente de sucesos:

"Mi año y medio en El Caso había estado lleno de satisfacciones profesionales. Su venta fue incrementada sustancialmente, superando los 200000 ejemplares. El semanario había cambiado de cara -pasó de imprimirse en las viejas rotativas tipográficas de Informaciones a las modernas de offset de Cosol- y ya no había que sacudirlo para que escurriera la sangre antes de leerlo, porque un 50 por ciento de los sucesos con sangre fueron sustituidos por 'casos' divertidos de la vida diaria de nuestra España cañí' (Caño Díaz, 2007). 
Casasús (1985b: 146) achaca el éxito de este periódico en esta década no sólo a los elementos de su contenido, sino también a sus factores morfológicos o de presentación:

"En realidad, el éxito de un semanario como El Caso [...] en la España de los 70 sólo puede atribuirse a un interés hegemónico por su contenido, del mismo modo que el galopante y mortal crecimiento de $L o o k^{4}$ en aquella misma época o el éxito de determinados programas de televisión dependen principalmente de factores ajenos al contenido".

Los años ochenta fueron los últimos de la administración de Eugenio Suárez. Jesús Carlos Fernández Sedano fue director hasta 1985, aunque siempre figuraba como "director en funciones". A principios de esta década, el semanario mantenía una buena salud, con tiradas que llegaron a los 400000 ejemplares, la más elevada de revistas en papel. Según indica Arias (2011), el periódico entró en los últimos años en crisis y bajaron las ventas; los corresponsales y colaboradores comenzaron a tener serios problemas con el cobro.

El 29 de agosto de 1987 salía a la calle el último número, al haber llegado a la quiebra. Rada cuenta que las causas que motivaron esta situación fueron económicas, derivadas de la competencia de otras incipientes empresas periodísticas y de problemas familiares de Eugenio Suárez:

"Llegó un momento en que El Caso, nave nodriza de su escuadrilla editorial, no pudo seguir tirando del resto de la formación. La salida al mercado de importantes revistas competidoras fue postergando a las de Suárez, a lo que se unían problemas económicos por su problemática vida familiar" (Rada, 2011: 42).

Arias enumera las causas principales que provocaron la desaparición de El Caso de Eugenio Suárez. El principio del fin fue la salida en 1980 de la periodista más popular de este semanario, Margarita Landi, quien se trasladó a la revista Interviú y consiguió doblar su tirada con la nueva incorporación. Otra causa, ya indicada, fue la ruinosa situación económica en la que se encontraba su editor, motivada por la separación y posterior divorcio de su esposa. Otra tiene más relación con el formato del periódico: su contenido y estilo ya no encajaba en los años ochenta, en una sociedad y unos lectores muy diferentes a los de 1952. Incluso, la reconversión de este periódico no cuajó en el público.

Barrera (1995: 82) también entiende que este semanario (que tanto éxito tuvo durante el régimen franquista) no llegó a triunfar en la democracia, ya que no supo o no pudo encajar en una España diferente a la de Franco. Por ese motivo, desapareció.

La segunda etapa de El Caso fue más corta y duró diez años. El periodista y empresario Joaquín $\mathrm{Abad}^{5}$ compró la cabecera y se convirtió en el nuevo propietario, centrándose fundamentalmente en la difusión de noticias sobre temática delictiva.

4 Se trata de una revista norteamericana con una tirada de ocho millones de ejemplares cuando dejó de imprimirse en 1971.

5 Arias señala, a modo de anécdota, que Abad (periodista que había sido anteriormente fundador y director del diario La Crónica, de Almería) llevaba diariamente a la redacción de El Caso un león, al estilo de Eugenio Suárez, quien también se caracterizó por tener alguna que otra mascota sorprendente en el periódico, como un cocodrilo. 
Durante una década, Abad luchó por mantener a flote la publicación. A pesar de ser rentable (vendía 120000 ejemplares por número), el incremento de los costes y las demandas, reclamaciones judiciales y pleitos que le interponían, provocaron el cierre definitivo del periódico. El 24 de septiembre de 1997 se imprimió El Caso por última vez. Abad, posteriormente, publicó la edición digital del semanario, pero sin lograr buenos resultados en Internet.

\section{Estilo}

El fundador de El Caso, Eugenio Suárez, marcó un estilo propio y característico de la información de sucesos durante los 35 años que fue responsable de este periódico. El contenido principal de sus noticias estaba relacionado con el mundo de los delitos y, dentro de estos, los asesinatos eran los que ocupaban lugar preferente de las portadas. También eran muy valorados en sus páginas los sucesos curiosos y extraordinarios, hubiera sangre o no. Los delitos, sobre todo los homicidios y asesinatos, eran la temática más buscada para rellenar la primera página. En sus páginas interiores se publicaban sucesos muy variados, redactados en forma de crónicas y reportajes. El Caso era conocido en España como el periódico de la "crónica negra".

Jesús Carlos Fernández Sedano, uno de los directores de El Caso que más años permaneció en el cargo, aclara que a los responsables del semanario les interesaba periodísticamente la peculiaridad del crimen. Juan Carlos Arias (corresponsal de El Caso en Andalucía Occidental durante los años 1982 a 1985) señala que tenía que mandar semanalmente un tema a la redacción de Madrid, pero los temas eran variados y no tenía que ser necesariamente de contenido sangriento. Ahora bien, reconoce que las noticias de portada estaban casi siempre referidas a asesinatos:

"Yo era reportero de calle e iba acompañado por mi fotógrafo, Fernando Crespo. Mandaba mi colaboración todos los jueves, a través de carta urgente en el Expreso para que llegara a tiempo a Madrid. Cubría temas de todo tipo, tanto hechos curiosos como criminales: el 'Caso Torreblanca', de pederastia donde estaban implicados en Sevilla tres jesuitas; las apariciones en El Palmar de Troya y el Papa Clemente; homicidios, violaciones o casos extraordinarios como una entrevista que le hice a un señor que tenía 118 años" (Arias, 2008).

El estilo de El Caso era popular y sensacionalista, sobre todo por su presentación formal (grandes titulares de color rojo y algunas escabrosas fotos), pero no amarillista, puesto que no inventaba las noticias, sino todo lo contrario: buscaba en exclusiva los sucesos que acontecían en la calle y sus redactores lo difundían con un estilo claro, crudo y directo.

La venta y el éxito popular del periódico dependían de los acontecimientos luctuosos de la época. Por este motivo disfrutó de una fuerte difusión y de unos lectores fieles. Eugenio Suárez cuenta, como una de sus anécdotas preferidas, la protagonizada por la gente analfabeta de los pueblos y pequeñas pedanías que aprendió a leer simplemente para poder enterarse de lo que contenía El Caso. San Andrés (1987: 83) califica al semanario de la siguiente forma: 
"La novela negra por entregas, que llegó a los rincones más apartados de la geografía española y, en su tiempo, el único vínculo con la información de muchos españoles”.

Algunos autores sólo recogen de este periódico su estilo sensacionalista, sin rescatar otras cualidades. "Sensacionalista periódico de sucesos", califica Barrera (1995: 82) al semanario ${ }^{6}$. El Caso no fue un periódico que sirvió para prestigiar las mesas de los despachos o las universidades, pero hay que reconocerle el mérito de crear un estilo propio y ofrecer un impulso al periodismo de sucesos y a la investigación periodística.

El contenido truculento de sus informaciones, sus portadas espectaculares con fotografías impactantes y la exageración intencionada en los titulares y en las noticias publicadas no favorecieron la seriedad del periódico. Sin embargo, también cumplió con algunos objetivos básicos del periodismo: el reporterismo "de calle", que implicaba la búsqueda de la noticia donde se producían los hechos; el acceso a las fuentes más directas, a los protagonistas de los sucesos, entrevistando los redactores en las cárceles a los asesinos o delincuentes. Los redactores de El Caso obtenían la información de fuentes policiales, sanitarias y judiciales y por ello eran asiduos de comisarías de Policía y cuartelillos de la Guardia Civil, juzgados, cementerios, depósitos de cadáveres, morgues, centros sanitarios o parques de bomberos.

Moreno Sardá (1998: 47) destaca, en cuanto al contenido temático de El Caso, que este semanario dedicaba más de la mitad de sus páginas a los sucesos de sangre, sobre todo a los homicidios. Con respecto a las fotografías e ilustraciones que complementaban el contenido de las informaciones, apunta que el semanario centraba más su atención en el ambiente en el que se había producido el suceso y no tanto en la víctima?

Muchos periodistas pasaron por la redacción de El Caso y escribieron sus trabajos con un estilo directo y sencillo, un uso generalizado de frases hechas y titulares llamativos y sensacionalistas. También crearon escuela con sus reportajes y crónicas de investigación criminal y delictiva, que han servido como fuente de inspiración para escritores de novela negra en España. Nombres como Enrique Rubio, Mariano R. Boix, Pedro Costa, o Margarita Landi marcaron un referente en la información de sucesos. Junto a otros redactores y periodistas, dieron un estilo propio a este periódico, basado en los reportajes "de calle" y de investigación.

Casasús (1985a: 166-167) incluye varios ejemplos, recogidos de El Caso, que ponen de manifiesto la importancia de lo que llama la "semantización" (realidad transformada) de los sucesos que suponen "protocolos de transformación" en el relato que los redactores envían al receptor. Algunos de los protocolos más empleados (en ediciones de 1973) son la

6 El propio Eugenio Suárez reconoce la utilización habitual del sensacionalismo en su semanario, aunque matiza que "un periodismo que no sea sensacionalista no es periodismo" (San Andrés, 1987: 83).

7 El Caso, asimismo, prestaba especial atención a temas extraordinarios, como aquellos relacionados con extraterrestres. En los años cincuenta publicó numerosa información sobre avistamientos de ovnis, viajes espaciales, contactos con seres de otras galaxias o visitas de alienígenas. Los lectores seguían con gran atención los reportajes que se publicaban sobre esta temática. Con secciones como "Busque aquí a su padre", El Caso fue también precursor de programas de televisión en España, como "Quién sabe dónde", de Francisco Lobatón, y emitido en TVE en la década de los noventa. 
sorpresa: "Unas horas de libertad para ir a la boda"; el flashback: "Aquel hombre acababa de degollar a su mujer, en la cocina de su casa, al parecer bajo la obsesión de unos celos carentes totalmente de fundamento"; o la simplificación: "Pesadilla en un pueblo amenazado por la contaminación". Otros protocolos utilizados son también los recursos humorísticos, la precisión policíaca, el apunte descriptivo, la retórica y la entrevista reconstruida.

Dentro de la plantilla de este semanario, la cronista más destacada fue Margarita Landi (1922-2004). Su verdadero nombre era Encarnación Margarita Isabel Verdugo Díaz y empezó a trabajar en El Caso en 1953, donde permaneció durante 28 años seguidos. Eugenio Suárez fue quien la introdujo en el mundo de los confidentes y de la policía, donde fue muy bien acogida, hasta el punto de que la Policía le mandaba un coche para recogerla cuando ocurría algún suceso espeluznante o la utilizaban como "gancho".

El estilo de El Caso está muy unido a Landi ${ }^{8}$, una reportera de calle, ya que siempre informaba en el mismo lugar donde sucedieron los hechos, como así hizo con sus reportajes sobre el crimen de Los Galindos y otros muchos. En opinión de Arias (2004), gracias a ella, el periodismo de sucesos cambió:

"Unánimemente se le consideró como decana y maestra del periodismo de sucesos, género que trasformó otorgándole categoría literaria y sólida base criminológica”.

Su línea editorial estaba muy marcada por el habitual tema protagonista de las portadas: los crímenes. En sus inicios, como no podía publicar más de un asesinato por número, se exaltaban los "éxitos" de la Policía y la Guardia Civil. Sus editoriales tenían un lenguaje sencillo y popular, con frases hechas y generalizaciones, sin entrar en análisis más profundos de tipo jurídico o sociológico.

En opinión de Rada (2011: 42), la segunda etapa de El Caso, capitaneada por Joaquín Abad (1987-1997), se caracterizó por la supresión en sus páginas de la crónica rosa, implantándose un estilo centrado exclusivamente en la publicación de noticias, reportajes y crónicas sobre el mundo del delito de forma sensacionalista.

\section{Portadas}

Hay que diferenciar el tratamiento de las portadas en el período comprendido entre 1952 a 1975 y posteriormente hasta su desaparición definitiva en 1997. Durante el Gobierno de Franco, las portadas de El Caso eran visualmente llamativas, con grandes titulares en letras de color rojo y grandes fotografías e ilustraciones impactantes (figuras 1 y 2), pero mesuradas, a fin de no "herir la sensibilidad de los lectores". Tras la muerte de Franco (1975) y al producirse la apertura democrática y de libertad de expresión, las portadas de El Caso se volvieron mucho más sensacionalistas. De ahí, que se haya generalizado la expresión de que las portadas de El Caso "chorreaban sangre", por la crudeza de las

8 Esta periodista autodidacta era conocida en la profesión como "Subinspectora Pedrito" o "la Rubia del Deportivo". 
fotografías que se publicaban ${ }^{9}$.

Era característico, sobre todo en los primeros años de existencia de El Caso, que los crímenes más llamativos ocuparan todas las portadas. Al evolucionar el diseño de las portadas, junto con la información destacada de los asesinatos, se insertaban también en la primera página otros titulares de sucesos llamativos en una columna y siempre con encabezados que señalaban el lugar donde se había producido el hecho. En ocasiones, determinados sucesos que no eran crímenes ocupaban un espacio preferente en las portadas y la noticia del asesinato era relegada a un segundo plano. En cualquier caso, la temática con mayor protagonismo en las portadas de El Caso eran generalmente los asesinatos.

El Caso abrió su primera portada con el enigmático y sangriento "Crimen en el Plantío", ilustrada con un dibujo de los dos presuntos asesinos que salían huyendo de un chalet. El pie de foto acompañaba la acción: "Por esta ventana saltó la muerte". En su tercera página ampliaba en su totalidad este suceso, en forma de crónica:

"La portada de este número reproduce exactamente el momento en el que Ángel Murciano y su cómplice huyeron por la ventana. Los asesinos, tras dar muerte a doña Rogelia en la cocina, salieron por la ventana asustados por el ruido del timbre del teléfono, que confundieron con el de la puerta. Grande tenía que ser su nerviosismo, ya que dicha ventana da sobre una terracita, justo al lado de la puerta principal y al borde de la carretera. Murciano, en nuestra portada, muestra en su gesto, magistralmente interpretado por José Pinédo, el rictus del criminal. Vestía chaqueta de pana y jersey de cuello alto" (El Caso, 11/V/1952, p. 3).

Entre otros ejemplos, podemos citar la noticia de un crimen, ilustrada con una fotografía de la presunta asesina (figura 2), acompañada de un gran titular en mayúsculas y letras en rojo ("La envenenadora de Algemesî"). En el pie se puede leer lo siguiente: "En la villa valenciana de Algemesí ha tenido lugar un espantoso crimen. Un matrimonio, compuesto por Francisco Mollá y Josefa Mas, ayudados por una bruja, envenenaron a Miguel Lerma con arsénico. En la foto, Josefa, inductora y autora del hecho". En todo caso, la noticia principal del número 674 de El Caso presentó un siniestro ("Cincuenta muertos en accidente aéreo. Un avión español cayó al mar cerca de Tánger”) y no un crimen. El pie reza de la siguiente manera:

"Patética escena de recuperación de las víctimas. El señor Gotfred, uno de los tres supervivientes (todos extranjeros) del trágico accidente del avión español 'Convair Metropolitan', que como informamos en páginas interiores cayó al mar a tres millas de Tánger momentos antes de iniciar el aterrizaje. Los únicos españoles que viajaban en el avión eran los cinco miembros de la tripulación, entre ellos una azafata de dieciocho años que hacía su primer vuelo. Todos han perecido en el accidente" (El Caso, 3/IV/1965).

9 Eugenio Suárez, fundador del semanario, está en desacuerdo con ese tipo de apreciaciones: "No chorreaba sangre porque estuvo racionado por el régimen de Franco a un suceso mortal por número. Y en aquella época se mataba poco y mal. Se hacía un periodismo duro, exigente, difícil, surgido en la desolación informativa de una coyuntura histórica determinada, que entretenía la curiosidad -morbosa si ustedes quieren- de miles de lectores" (ápud Rodríguez, 2008). 
Las primeras portadas tenían un diseño más cercano al folletín y a las publicaciones que aparecieron en España a principios de los años XX, donde un determinado suceso ocupaba toda la primera página, representado mediante un elaborado dibujo y un título, a modo de cubierta de una novela, en la parte inferior. En las portadas de los años cincuenta era habitual que aparecieran con ilustraciones del dibujante Pinédo ${ }^{10}$ que reconstruían gráficamente los hechos acontecidos (figura 1).

Casos como el de la "Mano cortada" y especialmente el "caso Jarabo" (1959), llevaron al semanario a vender 400000 ejemplares. El caso de "El Lute", entre los años sesenta y setenta, también despertó el interés nacional. A medida que avanzaba la década de los cincuenta, las portadas del periódico evolucionaron ${ }^{11}$, insertando una información central y otras noticias breves, que iban en una columna (generalmente en la parte izquierda de la portada), bajo el encabezamiento "En este número".

En los años sesenta, la portada del periódico se moderniza más, aunque sin dejar de lado los titulares llamativos y grandes fotos que ilustran la información principal (figura 3). El ancho de la cabecera se redujo para insertar, en la parte superior derecha, un recuadro a modo de flash informativo. En la siguiente década, el periódico se adaptó a los nuevos cambios tras la muerte de Franco. Ya no se incluirán solamente "sucesos", sino también noticias “del corazón" (llamada también "crónica rosa”) y otras informaciones de sociedad ${ }^{12}$. Sin embargo, a partir de los años ochenta, las portadas de El Caso fueron más sensacionalistas ${ }^{13}$ y recogieron imágenes que "chorreaban sangre" (figura 4).

10 Las portadas ilustradas por Pinédo durante el año 1952 incluyeron titulares como: "Vació el cargador sobre el secretario de la Fiscalía de Tasas"; "Al ver que se me echaba encima, le tiré una pesa"; "Aquí encontré muerta a mi madre"; "Puente de mando del platillo volante"; "El pistolero me atizó una patada en la boca"; "Así es el timo de 'las borregas””; “Manos arriba!”; "El misterio de la mano cortada”, entre otros. En décadas posteriores primó la fotografía como elemento gráfico más destacado.

11 Junto con la presentación de las noticias, también cambió el diseño de la cabecera del periódico. En sus primeros números aparecía, bajo un fondo rojo, El Caso, con gruesas letras mayúsculas y de color blanco y debajo el subtítulo: "Semanario de sucesos" (en la década de los setenta se tornaría a "Semanario popular"). Ocupaba toda la franja superior de la portada. En números posteriores se emplearon tipos más estilizados e incluyendo en su cabecera el número del ejemplar y el precio.

12 En su XXV aniversario, El Caso lanzó un número especial (1977), donde se presentó una extensa entrevista a un célebre delincuente ("El Lute"), una narración de Camilo José Cela y otra de Margarita Landi, así como una especie de antología de noticias publicadas en el semanario bajo los rótulos: "Los cinco crímenes más recordados", "Los 25 casos más insólitos" y "Las 25 fotos más desgarradoras".

13 Ejemplo de algunos de los titulares, en 1983: "La tiró de cabeza al vacío", "Le mató por no dejarse violar", "Quemó vivos a los infieles", "Le despedazó el amor", "Les pillaron enterrándole". 
Figuras 3 y 4: portadas del semanario El Caso.
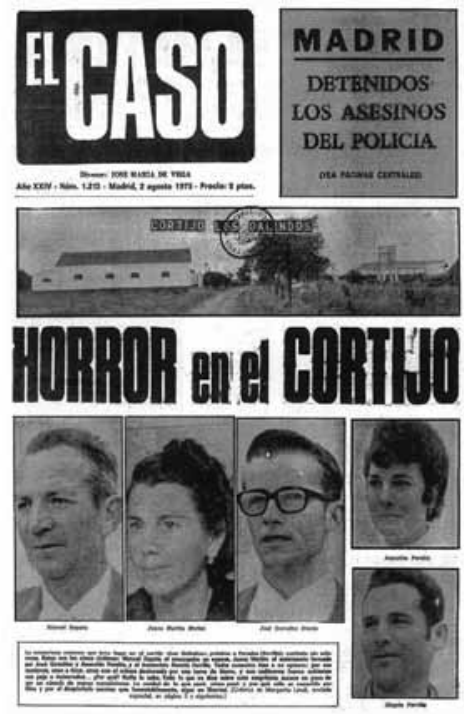

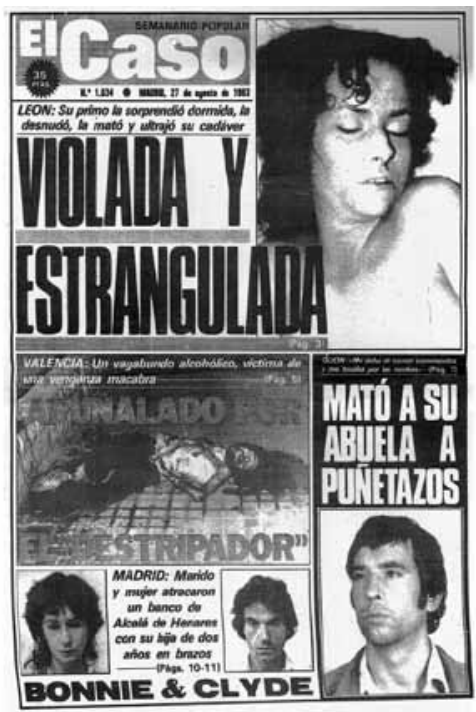

Fuente: archivo personal.

No hay duda que este semanario buscó, a través de sus portadas, impactar dramáticamente a sus lectores, mediante la cobertura extensiva de asesinatos. Arias (2011) destaca esa tendencia ${ }^{14}$ :

"En mi condición de corresponsal en Andalucía, desde Madrid los encargos que me pedían eran sobre todo asesinatos, temas de corrupción policial o casos insólitos. Los llamados antes crímenes pasionales eran siempre portadas en El Caso y los casos insólitos. Me publicaron unas ocho portadas, con sucesos como 'Los Quintillizos de Huelva', 'El Palmar', un loco que mató a su madre en el barrio sevillano de Nervión, policías corruptos que fueron detenidos en Sevilla por narcotráfico o el "Caso Torreblanca"'.

\section{Grupo de prensa}

Eugenio Suárez constituyó en España, en pleno régimen de Franco, una empresa periodística muy rentable, siendo precursor de lo que a finales de los años noventa serían los grandes grupos de comunicación españoles. Gracias a la rentabilidad de $E l$ Caso $^{15}$, Suárez fue fundador y propietario de una cadena de revistas y magazines especializados como Sábado Gráfico $^{16}$, Velocidad, Discóbolo, Aire Libre, Burladero, La Bota, Cine en 7 Días, Tu Salud, el satírico El Cocodrilo Leopoldo y otras publicaciones menores.

14 En todo caso, el propio Arias (2011) asegura que en las páginas interiores de El Caso aparecía información diversa, investigaciones periodísticas, corrupción policial y otras noticias “querellables".

15 El Caso tuvo algunos competidores que desaparecieron al poco tiempo. Entre estos, cabe mencionar al barcelonés Por qué, de Enrique Rubio (otrora redactor de El Caso) y Crimen y Castigo.

16 El semanario Sábado Gráfico se reconvirtió en una revista de información general durante la transición democrática, colaborando escritores como José Bergamín, Álvaro Cunqueiro, Alfonso Ussía y Antonio Gala. 
El propio Suárez reconoce que gracias a El Caso pudo mantener su independencia y crear su imperio periodístico:

“El Caso me dio la independencia, porque me dio mucho dinero. Así que nadie me podía comprar. Yo pensaba: quiero un yate, porque estaba seguro que cualquier día podía comprármelo. Uno es rico cuando tiene más dinero del que puede gastar y a mí me pasó durante muchos años" (ápud Fernández, 2009).

Estas publicaciones fueron líderes en sus segmentos y especialidades. Forman parte de la reciente historia del periodismo popular de la segunda mitad de siglo XX en España. Aún así, ninguna de las publicaciones del grupo de prensa de Eugenio Suárez circula en la actualidad ${ }^{17}$ , desapareciendo una forma de informar, basada en el ingenio, el estilo claro, las exclusivas, el reporterismo "de calle" y el contacto con los lectores.

De acuerdo con Suárez, la clave que resumiría el éxito comercial de El Caso residió en múltiples factores que tampoco ha llegado a comprender del todo: "Encajó, cayó muy bien y nació en su momento justo" (Daimiel, 2012).

\section{Fuentes consultadas}

- $A B C$, diario (1976, Septiembre 30). Sevilla.

- Arias, J.

_(2011, Noviembre). Entrevista personal.

_(2008, Junio). Entrevista personal.

_(2004). "La flor del crimen”. Extraída el 3/X/2012 desde http://gangsterera.free.fr/ PersMargaritaLandi.htm

- Barrera, C. (1995). Periodismo y franquismo. De la censura a la apertura. Barcelona: Eunsa.

- Caño, J. (2007). "Revistas, un decálogo subjetivo”. Extraída el 2/X/2012 desde http:// www.el-medio.com/libro/index.php?id=48

- Casasús, J.

_(1985a). "El suceso como ideología”, pp. 164 y ss. En AA. VV. Ideología y análisis de medios de comunicación. Barcelona: Mitre.

_(1985b). "La dialéctica entre redundancia y novedad", pp. 146 y ss. En AA. VV. Ideología y análisis de medios de comunicación. Barcelona: Mitre.

- Daimiel, radio (2012, Enero 24). "Eugenio Suárez: 'Muchos periodistas maltratan su herramienta de trabajo, el idioma'. Extraída el 3/X/2012 desde http://www.daimiel.es/ ptr/vista/ vptr002/post.html?D.k=2493699

17 Suárez donó a la Facultad de Periodismo de la Universidad CEU San Pablo (Madrid) las colecciones de las catorce cabeceras del grupo que creó, incluida la de El Caso. 
- El Caso, diario. Ediciones consultadas del período 1952-1987. Madrid.

- El Mundo, diario (1993, Marzo 16). Madrid.

- Fernández, S. (2009, Mayo 10) “El semanario ‘El Caso’ me permitió la independencia, porque me dio mucho dinero" [Entrevista a Eugenio Suárez]. La Nueva España. Extraída el 3/X/2012 desde http://www.lne.es/aviles/2009/05/10/semanario-casopermitio-independenciadiodinero/754761.html

- Moreno Sardá, A. (1998). La mirada informativa. Barcelona: Bosch.

- Quesada, M. (2007). Periodismo de sucesos. Madrid: Síntesis.

- Rada, J. (2011). 60 Aniversario de El Caso. Semanario de sucesos. Málaga: Grupo Editorial 33.

- Rodríguez, J. (2008, Septiembre 4). "El misterioso caso de 'El Caso': desaparece su archivo gráfico". El Economista. Extraída el 3/X/2012 desde http://ecodiario. eleconomista.es/ cultura/noticias/733718/09/08/El-caso

- San Andrés, M. (1987). “El Caso, 35 años de crónica negra”. Periodistas, núm. 4, Madrid.

- Umbral, F. (1993, Marzo 16). "Los sucesos”. El Mundo, p. 7. 